\title{
Ectopic pregnancy: a cause for maternal morbidity
}

\section{Priyadarshini B., Padmasri R.*, Jnaneshwari T. L., Sowmya K. P., Urvashi Bhatara, Hema V.}

Department of Obstetrics \& Gynaecology, Sapthagiri Institute of Medical Sciences and Research Centre, Bangalore, India

Received: 01 January 2016

Accepted: 08 February 2016

\section{*Correspondence:}

Dr. Padmasri R,

E-mail: drpadmasuraj@gmail.com

Copyright: $(\odot$ the author(s), publisher and licensee Medip Academy. This is an open-access article distributed under the terms of the Creative Commons Attribution Non-Commercial License, which permits unrestricted non-commercial use, distribution, and reproduction in any medium, provided the original work is properly cited.

\section{ABSTRACT}

Background: Despite the scientific and technological advances maternal morbidity and mortality continue to occur across the globe with regional variation. Ectopic pregnancy is one such cause which contributes to devastating fate of pregnant ladies. Over a period of time there have been variations in the incidence, cause, clinical presentation and management of ectopic pregnancy. The objective is to observe variations with respect to incidence, cause, clinical presentation and management of ectopic pregnancy

Methods: The present study was a 1year prospective and 1 year retrospective study from Dec 2012 to Nov 2014 at a tertiary medical college in Karnataka. All diagnosed cases of ectopic pregnancy were enrolled in the study. Statistical methods employed in the present study were contingency table, chi-square test and contingency coefficient analysis (cross tabs procedure).

Results: 38 cases were studied during two year period out of which $94.8 \%$ were tubal pregnancies, $2.6 \%$ each were cervical pregnancy and pregnancy in the rudimentary horn of the uterus. Maximum incidence of tubal gestation was noticed between the age group of 21-30 years (60.1\%). 55.2\% were nulliparous and 29\% were multiparas. Commonest mode of termination was rupture in $57.9 \%$ of the cases; tubal abortion was seen with haemoperitoneum in $26.3 \%$ of the cases.

Conclusions: Ectopic pregnancy remains a significant gynaecologic emergency, delay in diagnosis and treatment can be catastrophic, but early diagnosis and timely treatment can virtually eliminate need for surgical intervention.

Keywords: Ectopic, Pregnancy, Tubal

\section{INTRODUCTION}

Having an uneventful reproductive life is a blessing for any lady. Ectopic pregnancy is implantation of the fertilized zygote anywhere other than in the uterine cavity. It was first recognized by Busiere in 1693, when he was examining the body of a prisoner executed in Paris. ${ }^{1}$ Lawson Tait first performed the documented operation for ruptured tubal pregnancy in $1884 .^{2}$ Tanaka and colleagues reported the first use of systemic methotrexate for an ectopic pregnancy in $1982 .{ }^{1}$ Expectant management of ectopic pregnancy was extensively studied by Fernandez and associates in $1988 .{ }^{3}$ The management of ectopic pregnancy has changed over the last two decades. In line with this shift in practice, there has been a fourfold decrease in the mortality rate; although the incidence of ectopic pregnancy has increased twofold over the last 25 years. ${ }^{4}$ Complacency would be inappropriate, however, because ectopic pregnancy remains the leading cause of maternal death in early pregnancy. ${ }^{5}$

\section{METHODS}

This study was undertaken at a tertiary care hospital in Southern India between December 2012 and November 2014. Total number of deliveries during the study period was 2681 , live births were 2671 and we had 38 cases of 
ectopic pregnancy, giving an occurrence of 1.4/1000 deliveries. All women in reproductive age group (15-45 years) presenting with a missed period, vaginal bleed or pelvic cramping, currently pregnant based on urinary or serum $\beta$-hCG level and excluding intrauterine pregnancy, were included in the study. Statistical methods employed in the present study were contingency table analysis, chisquare test and contingency coefficient analysis (cross tabs procedure).

All patients were evaluated with necessary investigations, sample of blood drawn for grouping and cross-matching to arrange for blood transfusion when needed. In acute cases with typical features of amenorrhoea, pain and bleeding the diagnosis was confirmed by ultrasonography, followed by laparotomy. Patients in shock were treated and taken up for surgery. In cases with doubtful diagnosis, patients were observed after hospitalization and laparotomy done subsequently, if necessary.

Patients who met the criteria for medical management (haemodynamically stable with the ectopic gestational sac of less than or equal to $3.5 \mathrm{~cm}$ with no cardiac activity, with normal blood count, normal results of liver and renal function test) were administered a single dose of $50 \mathrm{mg} / \mathrm{m}^{2}$ of intramuscular methotrexate and followed up with serial serum $\beta$-hCG on day 1,4 and 7 and ultrasonography. All the surgical interventions were performed under general anaesthesia, laparotomy or laparoscopy as the condition necessitated.

\section{RESULTS}

There were 38 cases of ectopic pregnancy during the two year study period against 2681 deliveries with the incidence of $1.4 \%$. 23 were in the age group of 21-30 years $(60.5 \%)$. Nulliparous women constituted 21 $(55.1 \%)$ of these women and in twelve of them this was the first conception. Infertile women were $8(21.1 \%)$ followed by those who had previous abortions $4(10.5 \%)$ (Table 1). Multiple risk factors contributing in $4(10.5 \%)$ (Figure 1). The typical triad of amenorrhoea, pain abdomen and bleeding was observed in $42.1 \%$ of the cases. Amenorrhoea and pain abdomen were the most significant symptoms in $81.6 \%$ of cases. Other symptoms were either urinary disturbances or gastrointestinal (34\%). The patients with ampullary pregnancy had typical triad of symptoms. Infundibular pregnancies had pain abdomen as main complaint. Undetermined cases had amenorrhoea as the major complaint (Table 2).

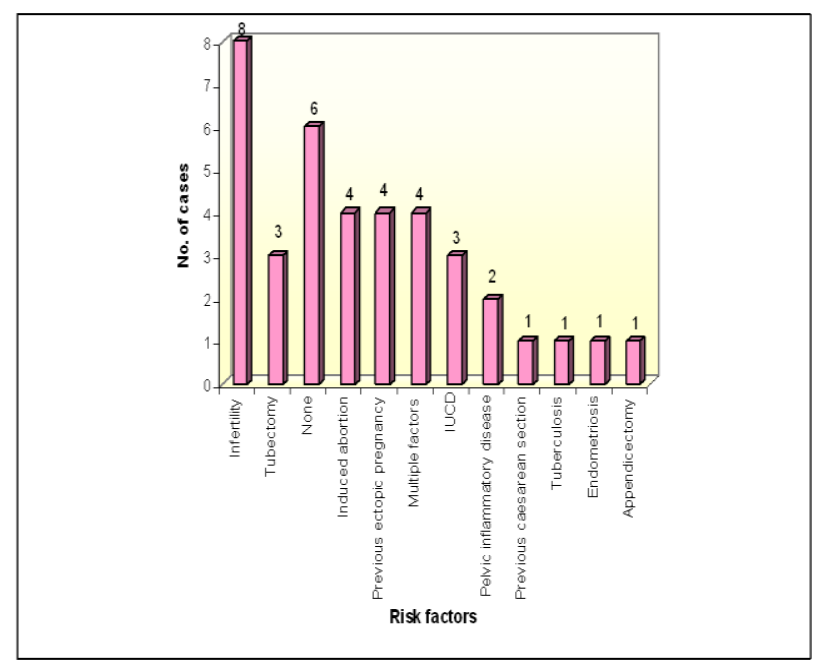

Figure 1: Risk factors in ectopic pregnancy.

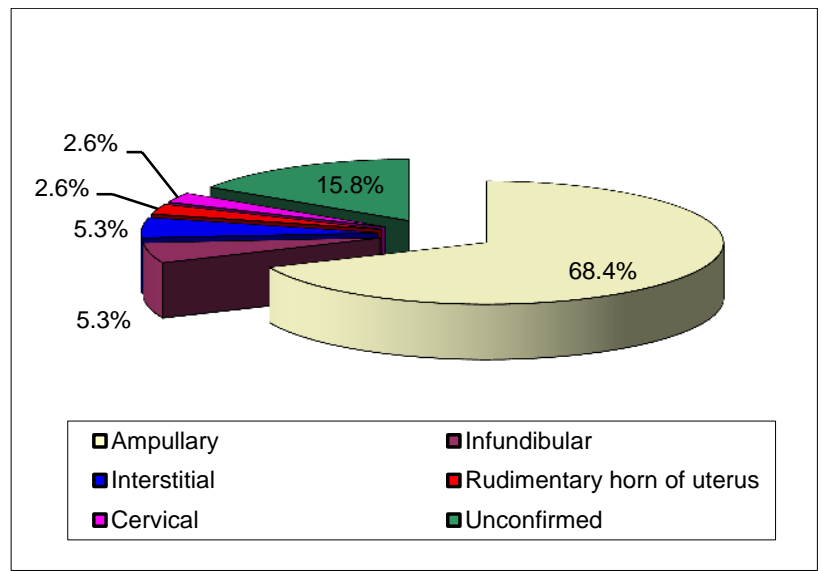

Figure 2: Site of ectopic pregnancy at treatment.

Table 1: Correlation of sample by age and parity.

\begin{tabular}{|llllll|}
\hline $\begin{array}{l}\text { Age group } \\
\text { (years) }\end{array}$ & Parity & $\mathbf{1}$ & $\mathbf{2}$ & $\mathbf{3}$ & Total \\
\hline $15-20$ & $4(80.0 \%)$ & $1(20.0 \%)$ & - & - & $5(100.0 \%)$ \\
\hline $21-25$ & $10(83.3 \%)$ & $2(16.7 \%)$ & - & $1(9.1 \%)$ & $12(100.0 \%)$ \\
\hline $26-30$ & $6(54.5 \%)$ & $2(18.2 \%)$ & $2(18.2 \%)$ & $2(29.7 \%)$ & $11(100.0 \%)$ \\
\hline $31-35$ & $1(14.2 \%)$ & $1(14.2 \%)$ & $3(42.9 \%)$ & $2(100.0 \%)$ & $2(100.0 \%)$ \\
\hline $36-40$ & - & - & - & - & $5(13.2 \%)$ \\
\hline $41-45$ & - & - & $1(100.0 \%)$ & $3(100.0 \%)$ \\
\hline Total & $21(55.2 \%)$ & $6(15.8 \%)$ & $6(15.8 \%)$ & $38(100.0 \%)$ \\
\hline
\end{tabular}

$\chi^{2}=30.087, \quad \mathrm{p}=0.012(\mathrm{~S})$ 
Table 2: Distribution of sample by site of ectopic pregnancy and mode of presentation.

\begin{tabular}{|lllll|}
\hline \multirow{2}{*}{ Site } & Mode of presentation & & & Others \\
\hline Ampullary & Amenorrhoea & Pain abdomen & Bleeding & Ot \\
\hline Infundibular & $19(13.1 \%)$ & $20(32.8 \%)$ & $18(29.5 \%)$ & $4(6.5 \%)$ \\
\hline Interstitial & $1(16.7 \%)$ & $3(50.0 \%)$ & $2(33.3 \%)$ & - \\
\hline Rudimentary horn & $2(50.0 \%)$ & - & $2(50.0 \%)$ & - \\
\hline Cervical & $1(50.0 \%)$ & - & - & $1(50.0 \%)$ \\
\hline Undetermined & $1(50.0 \%)$ & - & $4(28.6 \%)$ & - \\
\hline$\chi^{2}=14.757$ & $6(42.8 \%)$ & $4(28.6 \%)$ & & - \\
\hline
\end{tabular}

Out of 38 patients, four were admitted in a state of shock, of which 3 had ruptured, ectopic, one had tubal abortion and one had rudimentary horn rupture. Pallor was significantly seen in $47.6 \%$ of the cases. $60.8 \%$ and $57.1 \%$ of ruptured ectopic and tubal abortion cases respectively presented with pallor. Blood transfusion was required in $57.9 \%$ of patients and more than three units transfusion was necessitated in $10.5 \%$ of the patients.

Table 3: Distribution based on details of management.

\begin{tabular}{|lll|}
\hline Management detail & No. of cases & Percentage \\
\hline Unilateral salpingectomy & 18 & 47.3 \\
\hline $\begin{array}{l}\text { Salpingectomy with } \\
\text { contralateral segmental } \\
\text { resection of tube }\end{array}$ & 1 & 2.6 \\
\hline $\begin{array}{l}\text { Laparoscopy unilateral } \\
\text { salpingectomy }\end{array}$ & 3 & 7.9 \\
\hline Salpingostomy & 2 & 5.3 \\
\hline Suction evacuation & 1 & 2.6 \\
\hline $\begin{array}{l}\text { Unilateral salpingectomy } \\
\text { with ovarian cystectomy }\end{array}$ & 2 & 5.3 \\
\hline $\begin{array}{l}\text { Rudimentary horn } \\
\text { excision with unilateral } \\
\text { salpingectomy }\end{array}$ & 1 & 2.6 \\
\hline \begin{tabular}{l} 
Cornual repair \\
\hline $\begin{array}{l}\text { Medical management with } \\
\text { methotrexate }\end{array}$
\end{tabular} & 6 & 2.6 \\
\hline Bilateral salpingectomy & 1 & 15.8 \\
\hline $\begin{array}{l}\text { Unilateral salpingo- } \\
\text { oophorectomy }\end{array}$ & 1 & 2.6 \\
\hline $\begin{array}{l}\text { Hemoperitoneum } \\
\text { evacuation }\end{array}$ & 1 & 2.6 \\
\hline Total & 36 & 2.6 \\
\hline$\chi 2=58.591, p=0.000(H S)$ & 100.0 \\
\hline
\end{tabular}

$\chi 2=58.591, \quad \mathrm{p}=0.000(\mathrm{HS})$

Tenderness was significantly present in $81.5 \%$ of the cases. Distension and guarding were seen in about one third of the sample population. $15.8 \%$ of the patients were asymptomatic. At the time of treatment patient who had ruptured ectopic presented with typical symptomatic triad, whereas majority of patients with tubal abortion presented with pain abdomen. Patients with unruptured ectopic had different complaints in differing proportions. $65.8 \%$ of the cases had forniceal tenderness. Mass felt in the fornix was significantly less. Tenderness on abdominal examination was elicited in 54\% of ampullary, $50 \%$ of interstitial pregnancy significantly, while distension and guarding were observed in infundibular pregnancy. However, $13.4 \%$ of ampullary pregnancies and all of the ectopic gestation of unconfirmed site had no positive abdominal findings. Unconfirmed site of ectopic pregnancies have been presumed to be tubal ectopic pregnancies as suggested by ultrasonography. On abdominal examination, tenderness was commonly present in ruptured, unruptured and tubal abortions. But distension and guarding were exclusively present in ruptured ectopic gestation and in tubal abortions. 52.6\% of patients had bleeding per vaginum on speculum examination, most of which were seen in ruptured ectopic gestation and tubal abortions. Most of the cases had normal uterine size, however six cases had enlarged uterus. Cervical movements are painful in $57.9 \%$ of the patients which with the history and typical triad of symptoms was of utmost help in arriving at the correct clinical diagnosis of ectopic gestation. Urine pregnancy test, the simple test relied on in diagnosing the pregnancy status had a positive predictive value of 0.95 .In the present study, ectopic pregnancy was common on the right side.

Management of the cases was mainly surgical, followed by medical line of treatment. In case of ruptured tubal ectopic, decision for unilateral salpingectomy was made. Salpingectomy was considered in those who did not wish to conceive. The opposite site adnexa was conserved/salvaged based on the status of health of the tube. Those with medical management conservative procedure were advised for weekly follow up with $\beta$-hCG titre until it was $<15 \mathrm{mIU} / \mathrm{ml}$ (Table 3).

\section{DISCUSSION}

The occurrence of ectopic pregnancy in the present study was 1.4 per 1000 deliveries. This study shows an increase in the incidence over the past one year to the current year. The incidence of ectopic pregnancy in various studies was $1.7 \%^{6}, 1.5 \%^{7}$ and in the present study $1.5 \%$. The rising incidence may be due to the increased incidence of sexually transmitted disease. This may also be due to the better diagnostic modalities available and heightened awareness. ${ }^{8}$ Majority of the cases belonged to 21-30 years 
of age, but ectopic pregnancy can occur anytime in the reproductive age group. In the present study, maximum occurrence of ectopic gestation was seen in nulliparous. Some studies showed no specific relation to parity, ${ }^{9}$ but few reported that there is a decrease in the incidence of ectopic pregnancy with rising parity. ${ }^{7}$ In the ICMR multicentric case control study of ectopic pregnancy, majority of women were young and had low parity. ${ }^{10}$ In the present study, period of infertility ranged from 2 years to 9 years giving rise to $21 \%$ of the ectopic pregnancy. Significant incidence of prolonged infertility and its causal relationship to ectopic pregnancy has been observed by various authors. According to March Bank et al, ${ }^{11}$ Savitha Devi et al ${ }^{6}$ and Rose et al. ${ }^{7}$ Positive history of infertility was reported as $2.9 \%, 48.07 \%$ and $15.1 \% .^{8,9,11}$ Infectious disease has been an associated risk factor with variable magnitude in different studies. ${ }^{8,9,11,12}$ PID following Gonococcal, Chalamydial and other bacterial infection contribute to four fold increased risk of ectopic pregnancy. Relative risk as per ICMR multicentric case control study was 6.4. Many cases of Chlamydial salpingitis are indolent, may go unrecognized causing tubal damage and subsequent tubal pregnancy. A strong association has been incriminated between chlamydia infection tests for ectopic gestation. ${ }^{13}$ History of abortion in the past 2 years was obtained in $10.5 \%$ of the cases. Tubal damage or dysfunction following the previous abortion appears to be a factor in some cases. ${ }^{7}$ $10.5 \%$ of the cases in present series have had previous ectopic gestation. Recurrent ectopic has been reported in various studies ranging between $3.2 \%$ to $20 \%$. The risk of recurrent ectopic pregnancy was increasingly noted with history of surgery, history of live birth, and history of spontaneous miscarriage and not with a history of gonorrhea, chlamydia, pelvic inflammatory disease, caesarean section, or pregnancy termination. In our study, there were 7 patients with previous abdominal operations, 3 of which was tubal ligation (7.9\%), 2 were for ectopic gestation $(5.4 \%), 1$ was appendicectomy $(2.6 \%)$ and one was caesarean section (2.6\%). In the current series, $7.9 \%$ of the patients used IUCD. March Banks quoted an incidence of $1.6 \%$ for ectopic pregnancy in patients using progestin only contraceptive. IUCD association was noted in $11.9 \%, 7.69 \%$ of ectopic pregnancy. ${ }^{6,11}$ Multiple factors like infertility previous abortions, malformation of uterus and previous ectopic were noticed in $10.5 \%$ of our cases. One case of tuberculosis $(2.6 \%)$ on treatment was noted. Rose et al have reported tuberculosis as $3.2 \%$ of risk factors in their study. However, none of the risk factors could be associated in $15.9 \%$ of the patient in the present study. Rose et al reported no risk factors associated in $32.2 \%$.

Most of the symptoms and signs were produced by ruptured ectopic pregnancies or by tubal abortion with haemorrhage into the peritoneal cavity. The typical triad of amenorrhoea, pain abdomen and bleeding was noticed in $42.1 \%$ of the current study. The incidence of the same seen in other studies was $66.0 \%$ and $35.2 \%$ respectively. $^{7,15}$ None of the symptoms and signs is specifically pathognomonic of ectopic pregnancy, but combination of various findings is slightly suggestive of the condition. Presence of shock was seen in $9.5 \%$ of the patients. $9.7 \%$ of the cases series have said to have presented in shock. ${ }^{7}$ More acute the condition, more clear is the clinical picture. Therefore, undisturbed ectopic gestation is likely to be missed in most of the cases because of vague clinical features. Acute pain in the lower abdomen was the common presenting features in $81.6 \%$ of the cases with $40 \%$ of tubal rupture cases. Pain was absent in $24.2 \%$ of the patients may be due to the undisturbed ectopic or individual difference in the pain threshold. Amenorrhoea was present in $81.6 \%$ of the cases which is comparable to those reports of an incidence of $78.5 \%$ and $73 \%$ in their study. ${ }^{7,15}$ Absence of amenorrhoea in $23 \%$ of their cases was as conspicuous as $21 \%$ in the current study. Comparable reports of symptoms and signs of ectopic pregnancy in various studies are represented in the table below (Table 4). Vaginal bleeding of different patterns was noticed in $60.5 \%$ of the cases which was comparable to other studies. Other symptoms were giddiness in $7.3 \%$, retention of urine in $2.6 \%$ of the patients, nausea and vomiting in 6 patients $(15.7 \%)$, loose stools in $2.6 \%$ and dysuria in 6 patients $(15.7 \%)$. Oumachigui reported shoulder pain in $8 \%$, fainting attacks in $18 \%$, vomiting in $31 \%$ and urinary symptoms in $12.5 \%$.The classical sign of cervical movement tenderness was present in $57.9 \%$ of the patients. Ectopic nidation outside the fallopian tube is rare, $2.6 \%$ cervical in the present study and $2.6 \%$ in the rudimentary horn of uterus. A case series reported $1.4 \%$ of abdominal, $0.15 \%$ of ovarian and $0.15 \%$ cervical pregnancies. Bouyer et $\mathrm{al}^{16}$ reported $95 \%$ of tubal pregnancies in their study, others being ovarian $(3.2 \%)$, abdominal $(1.3 \%)$ and cervical $(<1 \%)$. It's been shown in an original study that $66 \%$ of the cases were diagnosed by ultrasonography as a complex adnexal mass and free fluid of $62 \% .^{7}$ But, on laparotomy haemoperitoneum was reported in $88 \%$ of the patients. In the present study $73.7 \%$ of the cases had haemoperitoneium with $57.9 \%$ of ruptured ectopic and $15.8 \%$ of the cases with tubal abortion. Since majority of our patients were referred from outside with established signs of ruptured ectopic pregnancy, they needed surgical radical approach as treatment. However, those diagnosed at an earlier period $(15.8 \%)$ with conditions having met were treated by medical management with single dose of methotrexate administration systemically. $10.6 \%$ of them were treated conservatively surgically. Gupta et al reported $1 \%$ of medical management in their series. However 1 of the 6 patients treated by medical methotrexate administration was failure as an immediate outcome. One more patient had recurrent ectopic on the same side after 10 months of previous treatment. When appropriately selected nonsurgical treatment is an effective and safe alternative to surgical method for unruptured ectopic pregnancy, more so important for nontubal ectopic pregnancies: interstitial, cervical and caesarean section scar pregnancies. Currently the initial human chorionic gonadotropin level probably remains the single most important predictor of 
success. $^{17}$ Concern for long-term reproductive performance should not be a factor in selecting between any of these four commonly used treatments for unruptured ectopic pregnancy. ${ }^{18}$ There was one postoperative morbidity with the wound infection. She was treated and discharged in good condition later on. Blood transfusion was necessitated in $57.9 \%$ of the patients intraoperatively and or post operatively.

Table 4: Risk factors for ectopic pregnancy.

\begin{tabular}{|lllll|}
\hline Risk factor & $\begin{array}{l}\text { March } \\
\text { Banks } \\
\text { et al }\end{array}$ & $\begin{array}{l}\text { Savitha } \\
\text { Devi } \\
\text { et al }\end{array}$ & $\begin{array}{l}\text { Rose } \\
\text { et al }\end{array}$ & $\begin{array}{l}\text { Present } \\
\text { study }\end{array}$ \\
\hline None & - & - & $32.2 \%$ & $15.9 \%$ \\
\hline OCP & $1.6 \%$ & - & - & - \\
\hline Tubectomy & $5.6 \%$ & $13.4 \%$ & $5.4 \%$ & $7.9 \%$ \\
\hline Induced abortion & $2.5 \%$ & $1.9 \%$ & $45.1 \%$ & $10.5 \%$ \\
\hline IUCD & $11.9 \%$ & $4.69 \%$ & $21.5 \%$ & $7.9 \%$ \\
\hline Previous ectopic & - & - & $3.2 \%$ & $10.5 \%$ \\
\hline Infertility & $2.9 \%$ & $48.0 \%$ & $15.1 \%$ & $21.0 \%$ \\
\hline Multiple factors & - & - & - & $10.5 \%$ \\
\hline Appendicectomy & - & - & - & $2.6 \%$ \\
\hline Prior caesarean & - & - & $7.5 \%$ & $2.6 \%$ \\
\hline PID & $4 \%$ & $25 \%$ & $34.4 \%$ & $5.4 \%$ \\
\hline Tuberculosis & - & - & $3.2 \%$ & $2.6 \%$ \\
\hline Endometriosis & - & - & - & $2.6 \%$ \\
\hline
\end{tabular}

\section{CONCLUSIONS}

While there is an increased incidence of ectopic pregnancy, mortality has dropped precipitously because of improved diagnostic and management modalities. Diagnosis rests on maintaining a high suspicion for women with symptomatic complaints in the first trimester or women without complaints but with risk factors. Most of our patients had surgical emergencies, as they were brought late with established diagnosis of ruptured ectopic pregnancies. Few of the patients diagnosed at earlier stage were given medical therapy. Ectopic pregnancy remains a significant gynaecologic emergency, delay in diagnosis and treatment can be catastrophic, but early diagnosis and timely treatment can virtually eliminate need for surgical intervention.

Funding: No funding sources Conflict of interest: None declared

Ethical approval: Not required

\section{REFERENCES}

1. Mark A, John A. Ectopic pregnancy. Te Linde's Operative Gynaecoloy. 10 ${ }^{\text {th }}$ Ed. Philadelphia: Lippincott Raven; 2008:501-27.

2. Carson Sandra A, John Buster E. Current concepts: ectopic pregnancy. N Engl J Med. 1993;329:117481.
3. Fernandez H, Rain horn JD, Papyri E. Spontaneous resolution of ectopic pregnancy. Obstet Gynecol. 1988;71:171.

4. Cahill DF. Bleeding and pain in early pregnancy. High Risk pregnancy management options, James. D.K, $3^{\text {rd }}$ Ed. Saunders, Elsevier; 2006:85-104.

5. Department of health; why mothers die: confidential enquiry into maternal deaths in the United Kingdom. In Drife J, Lewis G (eds): Norwich,UK:HMSO. 2001;282.

6. Savitha Devi Y. Laparoscopic treatment of ectopic pregnancy. J Obst Gyn India. 2000;50:69.

7. Jophy R, Thomas A, Mhaskar A. J Obst and Gyn India. 2002;52:55-8.

8. Stabile I, Grudzinski JG. Ectopic pregnancy; what's new? In Studd J editor. Progress in obstetrics and gynaecology, Vol 11. Edinburgh:Churchill Livinstone; 2000:11:281.

9. Eastman NJ, Hellman L. Williams Obst. $12^{\text {th }}$ edition. New York: Appleton century crafts; 1961:130.

10. ICMR task force project. Multicentric case control study of ectopic pregnancy in India. J Obst Gyn India. 1990;40:425-30.

11. Marchbanks PA, Annegero JF, Coullan CB, Strathy JH, Kurland LT. Risk factors for ectopic pregnancy. A population based study. JAMA. 1988;259:1823-7.

12. Bouyer J, Coste J, Shojaei T, Pouly J, Fernandez H. Risk factors for ectopic pregnancy: a comprehensive analysis based on a large case-control, populationbased study in France. Am J Epidemiol. 2003;157(3):185-94.

13. Butts S, Sammel M, Hummel A, Chittams J, Barnhart K. Risk factors and clinical features of recurrent ectopic pregnancy: a case control study. Fertil Steril. 2003;80:1340.

14. Brunham RC, Binns B, McDowell J, Paraskevas M. Obstet Gynecol. 1986;67:722.

15. Gupta U, Sharma P. Ectopic pregnancy- a prospective analysis of 100 cases. J Obst Gyn India. 1992;42:597-600.

16. Bouyer J, Coste J, Fernandez H. Sites of ectopic pregnacy: a 10 year population based study of 1800 cases. Hum Reprod. 2002;17:3224-30.

17. Kirk E, Bourne T. The nonsurgical management of ectopic pregnancy. Curr Opin Obstet Gynecol. 2006:18(6):587-93.

18. Buster JE, Krotz S. Reproductive performance after ectopic pregnancy. Semin Reprod Med. 2007;25(2):131-3.

Cite this article as: Priyadarshini $\mathrm{B}$, Padmasri R, Jnaneshwari TL, Sowmya KP, Bhatara U, Hema V. Ectopic pregnancy: a cause for maternal morbidity. Int J Reprod Contracept Obstet Gynecol 2016;5:7004. 